\title{
Identification of apomixis in the Kentucky bluegrass (Poa pratensis L.) using auxin test
}

\author{
Janetta Niemann*, Andrzej Wojciechowski, Jowita Janowicz \\ Department of Genetics and Plant Breeding, Poznań University of Life Sciences, Dojazd 11, 60-632 Poznań, Poland
}

\section{Abstract}

The effect of auxin treatment on the formation of apomictic - endospermless grains in Poa pratensis was investigated in the study. Four polish cultivars: Skiz, Eska 46, Alicja, Ani as well as six breeding lines: POB 13, SK-W-33, SKW-15, SKW-35A, SK-W35A and SK-W-35B were tested by embryological methods to reveal the reproduction pathway in greenhouse and field conditions. The obtained results showed that four genotypes, i.e. Alicja, Ani, Eska 46 and SK-W-35B are facultative apomictic and the other have formed seeds only on the apomictic way. In facultative apomicts it was found that in many cases both endospermless ovules containing embryo sacs with embryos or embryo sacs with well developed endosperm were formed. In the case of apomictic genotypes only endospermless seeds were observed.

Keywords: apomixis, embryo sac, Poa pratensis, auxin test, endosperm, ovules, parthenogenesis

\section{Introduction}

Kentucky bluegrass Poa pratensis L. is a valuable crop, especially under temperate climatic conditions. It could be used for many purposes including livestock feeding and lawn planting. $P$. pratensis reproduces primarily by apomictic way [1] and is characterized by facultative apomixis, i.e. the same genotype can yield both apomictic and amphimictic seeds [2]. There are two main processes of apomictic reproduction: unreduced embryo sac formation from a somatic cell of the nucellus and parthenogenetic development of apomictic grains in such aposporous embryo sac [3]. Because seeds do not develop without pollination, the type of apomixis is classify as pseudogamous, i.e. combining the development of an unfertilized ovule and the hybrid endosperm [4]. The most widespread form of apomixis in Kentucky bluegrass is apospory, which ensures preservation of the maternal genotype in seedlings [5]. This is the reason of intensive work concerning apomixis research aimed at producing monogenotypic bluegrass cultivars [6-8]. These experiments cannot be performed without studying different types or apomixis mechanisms and developing reliable methods of apomixis identification in wild and cultivated forms of Poa. There are different techniques of apomixis screening and estimating their frequency $[9,10]$.

\footnotetext{
* Corresponding author. Email: niemann@up.poznan.pl

This is an Open Access digital version of the article distributed under the terms of the Creative Commons Attribution 3.0 License (creativecommons.org/licenses/by/3.0/), which permits redistribution, commercial and non-commercial, provided that the article is properly cited.
}

But almost all of them are based on morphological stability of progenies or cytological observations that are difficult and time consuming. The simple method of apomixis identification in Gramineae is an auxin test, developed by Matzk [11]. It is based on the finding that in Poaceae a simple application of synthetic auxin at anthesis induces grain formation without fertilization. This is a procedure [11-13] which estimated the asexual potential as the frequency of auxin induced, endospermless grains containing one or more parthenogenetic embryos. Because parthenogenesis is one of the two main steps in asexual seed production, it gives an estimation of the apomictic capacity of selected plants. Auxin test could be useful for the grass breeders, which should be testing new breeding lines, before the registration of a new variety of $P$. pratensis for DUS (distinctness, uniformity and stability) tests in the Research Centre for Cultivar Testing (COBORU) at Słupia Wielka when it is required to write the percentage of apomixis [14].

The aim of this study was to investigate the parthenogenetic response of different Poa genotypes on auxin treatment in the field and greenhouse conditions.

\section{Material and methods}

Four polish cultivars: Skiz, Eska 46, Alicja, Ani and six breeding lines: POB 13, SK-W-33, SKW-15, SKW-35A, SK$\mathrm{W}-35 \mathrm{~A}$ and SK-W-35B of $P$. pratensis L. were investigated. The seeds of these genotypes originated from the Małopolska Plant Raising - HBP Ltd., Poland. All genotypes were grown both in a greenhouse and in the field conditions in nursery of Department of Genetics and Plant Breeding, Poznań University of Life Sciences. First, the individual genotypes of Poa were cloned in earlier mentioned two environments and further studies on these clones were conducted. It was ten clones for each 
genotypes. For identification of plants being either incapable or capable for parthenogenesis, modified auxin test was used [11]. Plants were treated with 2,4-dichlorophenoxyacetic acid (2,4-D) in may 2009 and 2010. In 2009 - the first year of our research panicles were sprayed directly before anthesis with 2,4-D in concentrations 40,80 and $120 \mathrm{mg} \times \mathrm{L}^{-1}$. However, the results obtained were comparable, so we decided that panicles will be sprayed only with an $75 \mathrm{mg} \times \mathrm{L}^{-1}$ solution of 2,4-D. Each year five inflorescences from three chosen clones of each genotype were soaked for one minute in these solution of synthetic 2,4-D. The paper bags were used for isolation. For further observation, one treated and one untreated inflorescence from three clones of each genotype were taken in the same time. Spikelets were sampled from the experimental field and from the greenhouse 25 days after spraying. Six spikelets from the panicle were collected and fixed in the solution of ethyl alcohol:chloroform:acetic acid (6:3:1) for $24 \mathrm{~h}$ and stored in $70 \%$ ethanol in the refrigerator until use. Additional, spikelets from untreated inflorescences were also sampled to check the grain induction in the absence of the auxin treatment. Embryological analysis of embryo and endosperm formation were made with the help of paraffin section methods $[15,16]$. There were 720 ovules analyzed altogether. The observation of endosperm and embryos development in embryo sacs (ES) were made under the Nicon microscope.

\section{Results}

Ovules from the untreated spikelets collected from both analyzed environments contain ES with or nuclear or cellular endosperm almost in all tested genotypes (Fig. 1, Fig. 2). Moreover, it was observed that in untreated ovules collected from the field there were the high percent of developed endosperm (100\% in six genotypes) and low percent of embryos (from $0.0 \%$ - Pob 13 to $100 \%$ only in Ani). In contrast, untreated ovules collected from the greenhouse contained higher percent of embryos (100\% in 5 genotypes) and lower percent of endosperm than from the fields.

Auxin test analysis showed that ten studied Poa genotypes differs considerably in the mode of reproduction. In the field condition in four analyzed genotypes, i.e. Eska 46, Alicja, Ani and Sk-W-35B only $72.2-83.3 \%$ of seeds were formed in the apomictic way, because in addition to ES with embryos and without endosperm (Fig. 1, Fig. 3a), could be observed ES with normally developed embryos and endosperm (Fig. 3b). This data indicate, that these genotypes are facultatively apomictic. However, six remaining genotypes: Skiz, Pob13, SK-W-33, SKW-15, SKW-35A and SK-W-35A showed mostly asexual mode of reproduction and only ovules containing one or two embryo sacs with differentiated embryos and visible polar nuclei (Fig. 3c) and without endosperm were observed (Fig. 3c,d). In the greenhouse only in ovules of one genotype - Skiz, the high percent of ES with embryo and without endosperm (94.4\%) was observed (Fig. 3e). But the data obtained in our experiment pointed that in the greenhouse the effect of the auxin treatment was a bit better than in the field.

General percentage of ovules without endosperm and with developed endosperm was depending on genotypes and on environment (Tab. 1). After auxin test in the field the highest percent (100\%) of ES without endosperm - apomictic seeds was observed in four genotypes, i.e. Skiz, Pob13, Sk-W-33 and $\mathrm{Sk}-\mathrm{W}-35 \mathrm{~A}$. However, in the greenhouse the highest number

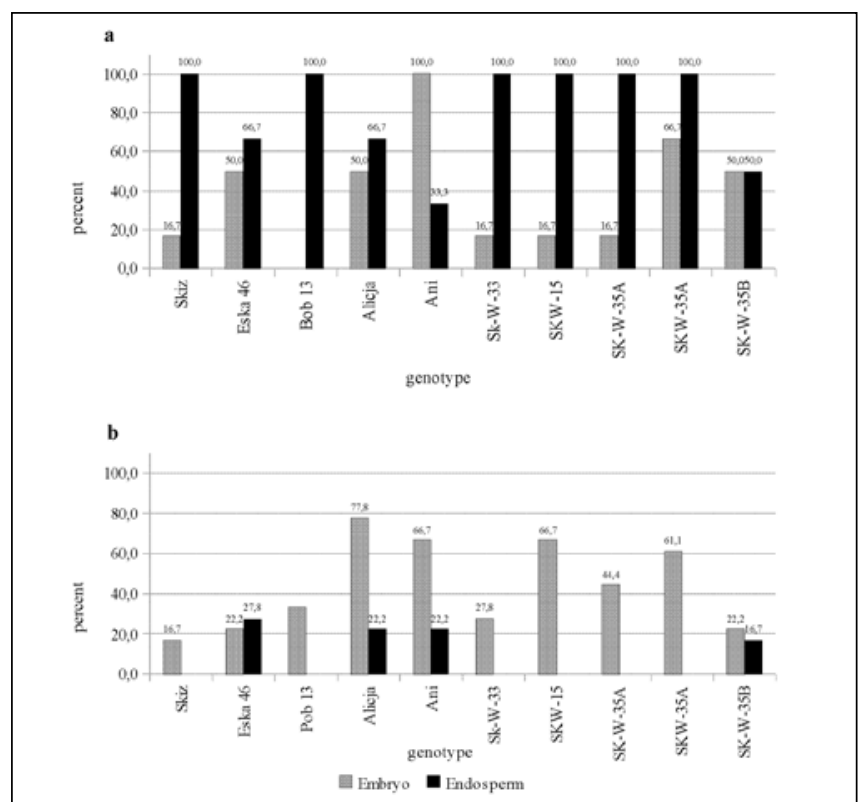

Fig. 1 Percentage of embryos and endosperm observed in: a auxin untreated; $\mathbf{b}$ auxin treated florets of 10 genotypes of Poa pratensis in the field condition.

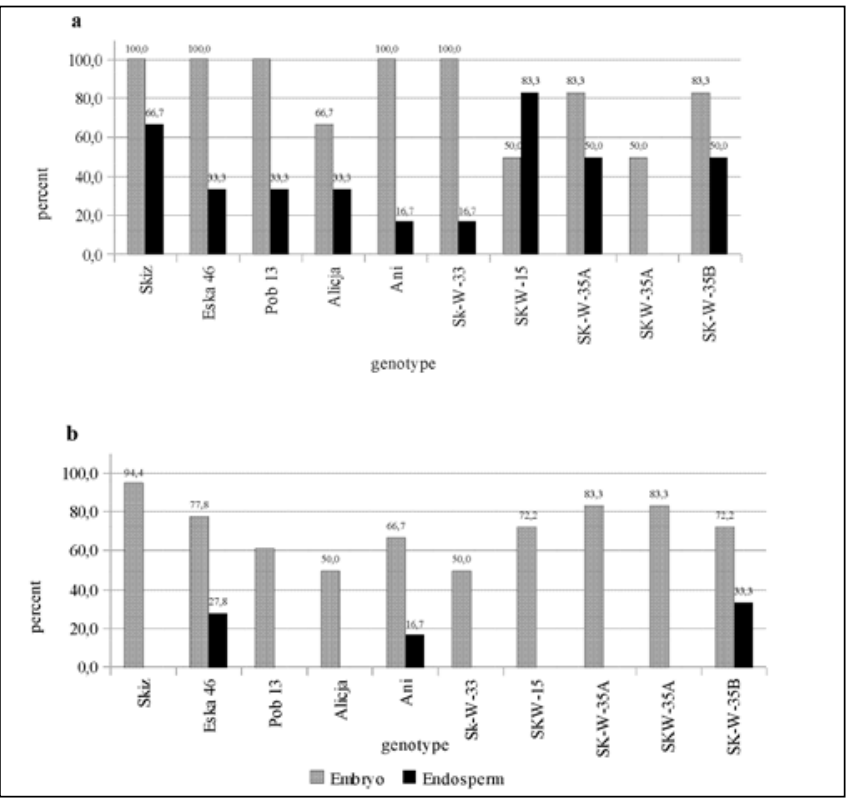

Fig. 2 Percentage of embryos and endosperm observed in: a auxin untreated; $\mathbf{b}$ auxin treated florets of 10 genotypes of Poa pratensis in the greenhouse.

of ES without endosperm was in the same genotypes as in the field conditions - except the breeding line SK-W-33 (only $44.4 \%)$.

Generally, in auxin treated spikelets taken from the field in all analyzed genotypes ES with differentiated embryos (16.7$77.8 \%$ ) were observed (Fig. 1). Cellular endosperm was found only in four genotypes, i.e. Eska 46 (27.8\%), Alicja (22.2\%), Ani $(22.2 \%)$ and Sk-W-35B (16.7\%). In contrast to the field condition, in spikelets after auxin treatment collected from the greenhouse, there was higher percent of ES with embryos (50-94.4\%; Fig. 2). Cellular endosperm was found only in ES of three genotypes, i.e. Ani, Eska 46 and SK-W-35B (16.7-33.3\%). 


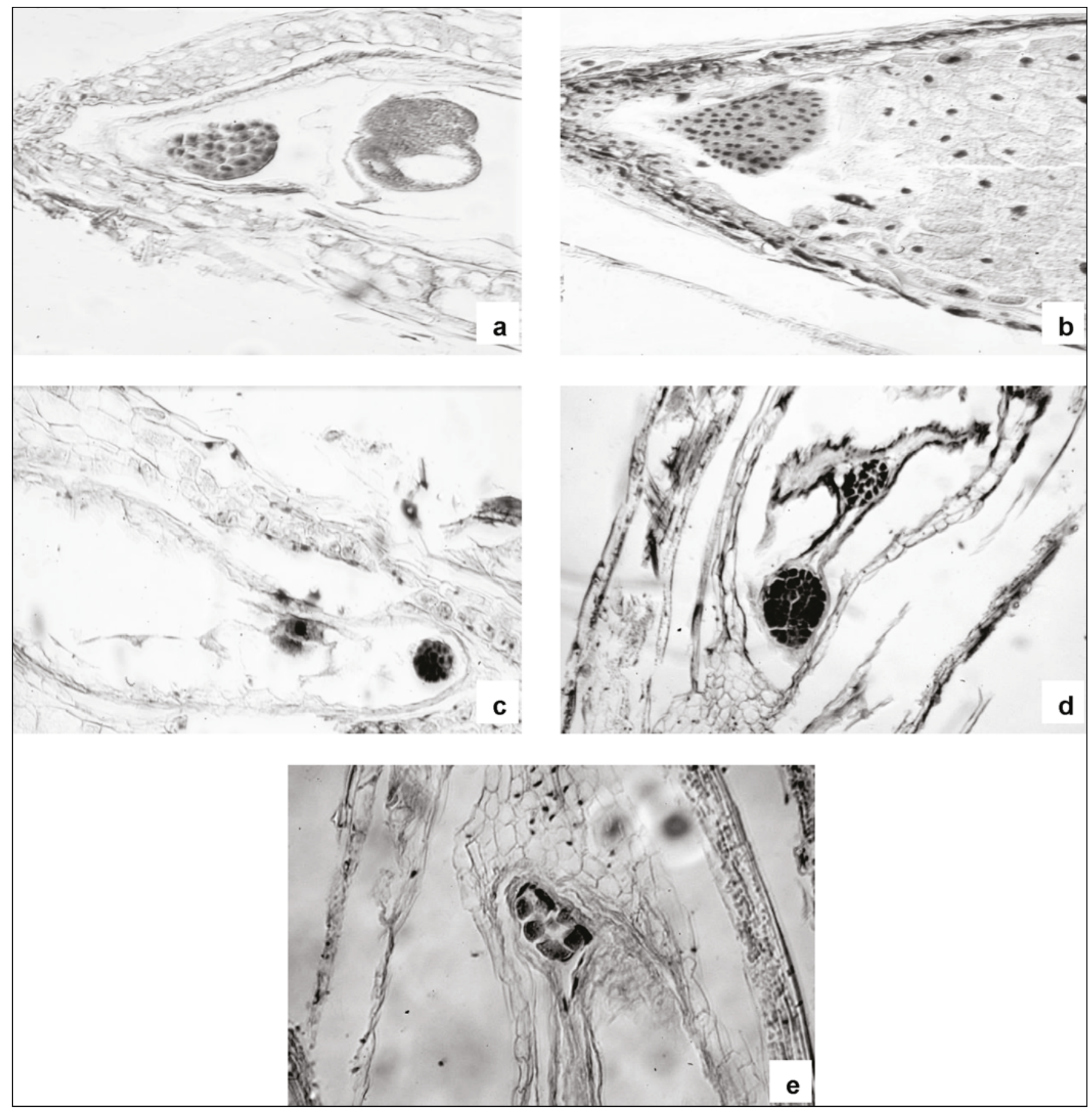

Fig. 3 Embryological analysis of auxin-induced ovules and grains in Poa pratensis genotypes. a-d Ovules collected from the field condition. a Ovule with globular shape embryo of Pob 13 line. To the right of embryo, antipodal cells are visible. b Embryo and developed, cellular endosperm in Eska 46 spiklet. c Globular embryo and polar nuclei formed in spikelets of Ani cultivar. d Two embryos formed in two ES of Alicja cultivar. e Ovule with embryo formed in one of two embryo sacs of Skiz cultivar, collected from the greenhouse.

\section{Discussion}

The study and other publications clearly demonstrated the importance of determining the characteristics of seeds reproduction in the Kentucky bluegrass ( $P$. pratensis L.). In our research the effect of 2,4-D, genotypes and environments on asexual way of seeds formation was investigated. It was shown that auxin test could be a good method for estimation the frequency of apomixis in Poa. It could be very useful especially because of the fact that in Kentucky bluegrass the most common mode of reproduction is a facultative aposporous parthenogenesis [17]. Moreover, in addition to the apomictic pathway, sexual reproduction involving fusion of reduced gametes is possible.
Our analysis confirmed the thesis presented above, because four of ten studied Poa genotypes proved to be a facultative apomicts (Eska 46, Alicja, Ani and Sk-W-35B). This also confirms the assumption adopted in our earlier work [18], where we indicate on two possibilities of seeds formation in Alicja and Ani cultivar - apomictic and sexual reproduction pathway. Expression of parthenogenesis was fairly stable within the analyzed clones, suggesting a strong genetic control. Although differences between environments and genotypes were evident. For example in the greenhouse after 2,4-D application in dose $75 \mathrm{mg} \times \mathrm{L}^{-1}$, more apomictic grains were formed comparing to the field conditions. Although, the dose of synthetic auxin applied in our experiments is comparable with another authors, i.e. Mazzucato [13] - $80 \mathrm{mg}$ 
Tab. 1 Average percent of ovules without endosperm for ten $P$. pratensis genotypes analyzed by the auxin test in two environments.

\begin{tabular}{|c|c|c|c|c|}
\hline \multirow[b]{4}{*}{ Genotypes } & \multicolumn{4}{|c|}{ Embryo sacs without endosperm (\%) } \\
\hline & \multirow{2}{*}{\multicolumn{2}{|c|}{$\begin{array}{c}\text { Field conditions } \\
2,4-\mathrm{D}\end{array}$}} & \multirow{2}{*}{\multicolumn{2}{|c|}{$\begin{array}{c}\text { Greenhouse } \\
2,4-\mathrm{D}\end{array}$}} \\
\hline & & & & \\
\hline & treatment & untreatment & treatment & untreatment \\
\hline 1. SKIZ & 100.0 & 0.0 & 100.0 & 33.3 \\
\hline 2. ESKA 46 & 72.2 & 33.3 & 72.2 & 66.7 \\
\hline 3. POB 13 & 100.0 & 0.0 & 100.0 & 66.7 \\
\hline 4. ALICJA & 77.8 & 33.3 & 100.0 & 66.7 \\
\hline 5. ANI & 77.8 & 66.7 & 83.3 & 83.3 \\
\hline 6. SK-W-33 & 100.0 & 0.0 & 100.0 & 83.3 \\
\hline 7. SKW-15 & 100.0 & 0.0 & 100.0 & 16.7 \\
\hline 8. SK-W-35A & 100.0 & 0.0 & 100.0 & 50.0 \\
\hline 9. SKW-35A & 100.0 & 0.0 & 100.0 & 100.0 \\
\hline 10. SK-W-35B & 83.3 & 50.0 & 66.7 & 50.0 \\
\hline
\end{tabular}

$\times \mathrm{L}^{-1}$, Matzk [11] $-50-100 \mathrm{mg} \times \mathrm{L}^{-1}$ or Szabo and Papp [19] $-100 \mathrm{mg} \times \mathrm{L}^{-1}$. Effects of the environment on the expression of apomixis were reported by several authors [15,20,21], but differences were always minor comparing to results obtained in presented work. More frequent cases of apomictic ovules observed in the greenhouse might be explained presuming that parthenocarpy can also be induced by natural stress such as heat. Grains with mature embryos without endosperms are found only in plants with genetically established parthenogenesis [11]. Our data indicate that in fully apomictic genotypes the development of ES was independent of environment. It was observed ES with embryos and without endosperm only. In contrast to the earlier researcher $[11,19]$, for observation the embryo and endosperm development we used the paraffin section methods. Probably that is why our data are not the same as for example in Matzk experiment [11], where after auxin treatment sexual plants formed seeds without endosperm and embryos at all. In our study developed endosperm (cellular endosperm) was observed in the ovules containing ES formed on a sexual way after auxin treatment. We confirm earlier observations which have been done by Szabo and Papp [19]. In their work, both the embryo and the weekly developed endosperm in sexual plants were observed.

The percent of endospermless seeds induction was satisfactory in our experiment. Values ranging between 60 and 100\% were slightly higher than reported by Matzk, 50-100\% [11], who used different synthetic auxins in combinations with other phytohormones, too. The frequency of induction shows a tendency to a genotype specificity, it was low in some genotypes (i.e. Alicja, Ani, SK-W-35B and Eska 46) and high in others (Skiz, SkW-15).

It is concluded that by using the auxin test four of ten studied Poa pratensis genotypes formed both apomictic and sexual seeds (Eska 46, Alicja, Ani and Sk-W-35B). Moreover, in greenhouse auxin treatment is slightly more effective than in the field condition, so this method could be especially recommended for greenhouses, where there is no rain and there is less diseases or insects.

It is therefore concluded that auxin test is a workable technique for determining the percentage of parthenogenesis in breeding programs. However, for the future research, the clearing-squash technique [22], could be recommended, which seems to be a good alternative, especially due to their timesaving.

\section{Acknowledgements}

The authors would like to thank Małopolska Plant Raising - HBP Ltd., Poland for providing Poa genotypes used in this research.

This work is part of the project "Flowering biology in chosen cultivars and strains of Poa pratensis with particular emphasis on apomictic way of seeds obtaining" founded by the Polish Ministry of Agriculture and Rural Development.

\section{References}

1. Müntzing A. Apomictic and sexual seed formation in Poa. Hereditas. 1933;17(2):131-154. http://dx.doi. org/10.1111/j.1601-5223.1933.tb02584.x

2. Agafonov AV, Sukhareva NB, Baturin SO, Struzhkina OA. Identification of apomixis in the Kentucky bluegrass (Poa pratensis L.) using SDS-PAGE of endosperm storage proteins. Biol Bull. 2004;31(1):36-41. http://dx.doi. org/10.1023/B:BIBU.0000014353.24452.8c

3. Wojciechowski A, Rokicki M. Apomixis and its importance in practical agriculture. Prace Komisji Nauk Rolniczych I Komisji Nauk Leśnych. 2006;100:212-218.

4. Nijs APM. Experimenting with apomixis and sexuality in Poa pratensis L. Apomixis Newsl. 1990;2:33-38.

5. Matzk F. Studies towards novel method in breeding the apomictic species Poa pratensis L. In: den Nijs APM, Elgersma A, editors. Fodder crops breeding: achievements, novel strategies and biotechnology: Proc 16th Meeting Fodder Crops. Eucarpia. Wageningen: Pudoc; 1991. p. 191-192.

6. Matzk F. Past and new project of apomixis research at Gattersleben. Apomixis Newsl. 1992;4:26-30.

7. Barcaccia G, Mazzucato A, Albertini E, Zethof J, Gerats A, Pezzotti M, et al. Inheritance of parthenogenesis in Poa pratensis L.: auxin test and AFLP linkage analyses support monogenic control. Theor Appl Genet. 1998;97(1):74-82. http://dx.doi.org/10.1007/s001220050868

8. Albertini E, Barcaccia G, Porceddu A, Sorbolini S, Falcinelli M. Mode of reproduction is detected by Parth1 and Sex 1 SCAR markers in a wide range of facultative apomictic Kentucky bluegrass varieties. Mol Breeding. 2001;7:293-300.

9. Czapik R. How to detect apomixis in Angiospermae. Polish Bot Stud. 1994;8:13-21.

10. Leblanc O, Mazzucato A. Screening procedures to identify and quantify apomixis. In: Savidan Y, Carman JG, Dresselhaus T, editors. The flowering of apomixis: from mechanisms to genetic engineering. Mexico: CIMMYT, IRD, European Commission DG VI; 2001. p. 121-134.

11. Matzk F. New efforts to overcome apomixis in Poa pratensis L. Euphytica. 1991;55(1):65-72. http://dx.doi.org/10.1007/ BF00022561

12. Matzk F. A novel approach to differentiated embryos in the absence of endosperm. Sex Plant Reprod. 1991;4(2):88-94. http://dx.doi.org/10.1007/BF00196493

13. Mazzucato A, Falcinelli M, den Nijs APM. Estimation of parthenogenesis frequency in Kentucky bluegrass with auxin-induced parthenocarpic seeds. Crop Sci. 1996;36(1):9. http://dx.doi.org/10.2135/cropsci1996.0011 183X003600010002x

14. Kłyś A, Jankun A. The biology of reproduction in Poa L. (Poaceae). Wiad Bot. 2002;46(3-4):19-28. 
15. Grazi F, Umaerus M, Åkerberg E. Observations on the mode of reproduction and the embryology of poa pratensis. Hereditas. 1961;47(3-4):489-541. http://dx.doi. org/10.1111/j.1601-5223.1961.tb01785.x

16. Grober K. Zytologische und embryologische Untursuchungen am Nucellus apomiktischer Sippen der Wiesenrispe (Poa pratensis L.). Kulturpflanze. 1986;34:147-158.

17. Bashaw EC, Funk RC. Apomictic grasses. In: Fehr WR, Fehr EL, Jessen HJ, editors. Principles of cultivar development. New York: Macmillan; 1987. p. 40-82. (vol 2).

18. Niemann J, Wojciechowski A, Świtoniak C. Studies on apomixis in chosen cultivars and breeding strains of Poa pratensis. Łąkarstwo w Polsce (Grassland Science in Poland). 2009;12:121-129.

19. Szabo Z, Papp M. Parthenogenetic capability of three species in Poa pratensis L. aggregation. Acta Biol Szeged. 2005;49:147-148.

20. Hovin AW, Berg CC, Bashaw EC, Buckner RC, Dewey DR, Dunn GM, et al. Effects of geographic origin and seed production environments on apomixis in Kentucky bluegrass. Crop Sci. 1976;16(5):635. http://dx.doi.org/10.2135/cropsc i1976.0011183X001600050009x

21. Williamson CJ. The influence of light regimes during floral development on apomictic seed production and on variability in resulting seedling progenies of Poa ampla and $P$. pratensis. New Phytol. 1981;87(4):769-783. http://dx.doi. org/10.1111/j.1469-8137.1981.tb01713.x

22. Herr JM. A new clearing-squash technique for the study of ovule development in Angiosperms. Am J Bot. 1971;58(8):785. http://dx.doi.org/10.2307/2441475 